\title{
Who buys certified firewood? Individual determinants of clean fuel adoption for promoting the sustainable energy transition in southern Chile
}

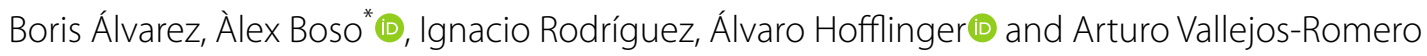

\begin{abstract}
Background: Temuco and Padre Las Casas, Chile, have severe problems of air pollution due to the extensive use of firewood for heating. The local authorities have made various efforts to improve fuel quality and introduce greater regulation into the market. Certified firewood guarantees low levels of humidity $(<25 \%)$ and has better combustion, but its distribution is still limited and the variables that determine its purchase have scarcely been studied. The aim of this study is to identify the determinants of certified firewood consumption in urban southern Chile.
\end{abstract}

Methods: This study was conducted with a cross-sectional non-experimental design. Following a non-probability sampling by convenience, we applied 355 surveys to participants who use a firewood system. Nonparametric comparisons analyses were made to identify differences in the use of certified wood by socio demographic variables. In addition, an Ordinal Logistic Regression was used to analyze the relation between the use of certified firewood and various psycho-social variables.

Results: Half of the users of wood-burning stoves participating in the study declared that they "never" (38\%) or "almost never" (12\%) used certified firewood to heat their home. Situational and product-related variables, such as price, availability, convenience and time are fundamental to people's purchase behavior, partially explaining the low public interest shown in this product. On the other hand, the results indicate the influence of socio-demographic variables such as income level and the presence of older adults at home, as well as psycho-social variables which include how much participants pay attention to air quality, the information level they have about it, the feelings of discomfort due to air pollution and concern for its effects on health.

Conclusions: First, increasing information levels and awareness among the population through communication campaigns is necessary to promote the sustainable urban energy transition in southern Chile. Second, information strategies may be complemented by boosting employment, driving investment, improving income, and strengthening the mechanisms of social protection, especially for the most vulnerable groups, to be effective. Finally, protecting and stimulating the formal trade in firewood could increase the points of sale of certified firewood, which would facilitate user access to cleaner fuels.

Keywords: Fuel choice, Energy, Certified firewood, Air pollution, Public policy, Chile

*Correspondence: alex.boso@ufrontera.cl

Universidad de La Frontera, Avenida Francisco Salazar 01145, Temuco,

Chile permits use, sharing, adaptation, distribution and reproduction in any medium or format, as long as you give appropriate credit to the original author(s) and the source, provide a link to the Creative Commons licence, and indicate if changes were made. The images or other third party material in this article are included in the article's Creative Commons licence, unless indicated otherwise in a credit line to the material. If material is not included in the article's Creative Commons licence and your intended use is not permitted by statutory regulation or exceeds the permitted use, you will need to obtain permission directly from the copyright holder. To view a copy of this licence, visit http://creativecommons.org/licenses/by/4.0/. The Creative Commons Public Domain Dedication waiver (http://creativeco mmons.org/publicdomain/zero/1.0/) applies to the data made available in this article, unless otherwise stated in a credit line to the data. 


\section{Background}

Every winter, the cities in urban southern Chile record pollution levels that exceed healthy limits established by the World Health Organization (WHO). Temuco and Padre Las Casas are a paradigmatic case, because in 2013, they were the first communes in the country, outside the Metropolitan Region of Santiago, to be declared a "saturated zone" due to particulate matter. The pollution levels in both communes have reached such a critical point that they are commonly found in the rankings of the most polluted cities in Latin America, surpassing capitals traditionally known for their poor air quality, such as Bogota, Mexico City, Lima or Santiago de Chile [1]. The worsening air quality in southern Chile is due to the extended use of firewood for heating and, to a lesser extent, cooking. According to data from the National Socioeconomic Characterization Survey (CASEN 2017), in Temuco and Padre Las Casas, more than $90 \%$ of households use firewood for heating or cooking, whereas in the rural areas of the region the proportion can be even higher. The combination of low income $50 \%$ of workers have a monthly income of 400 USD or less according to CASEN 2017), lack of access to alternative energies at a reasonable price (liquefied petroleum gas, kerosene and electricity can cost more than 3 to 5 times more per unit of energy), and a greater demand for energy due to poor quality construction of many of the houses explains the mass use of this fuel in the region.

To address this problem, the Ministry of Environment has implemented Atmospheric Decontamination Plans (ADP) in the main cities in the south of the country. ADP consists of a package of measures designed to: (i) promote the replacement of wood-burning stoves for more efficient devices; (ii) improve the thermal insulation of the houses; (iii) improve fuel quality; (iv) restrict the use of wood-burning stoves during health emergency periods; and (v) inform the population about the efficient use of energy and the health risks that air pollution entails.

A significant proportion of the firewood consumed as fuel in the households in southern Chile comes from the informal market, which brings with it a series of problems. In general, informal trade is related to unsustainable deforestation rates and the sale of wet firewood, which generates a worse fire and causes greater air pollution [2-4]. In addition, it harms certified dry firewood sellers and does not allow the State to collect funds to mitigate, among other things, the health issues derived from bad air quality.

In the developing world, several barriers limit the adoption of certification schemes, such as high certification costs, limited local willingness to pay for environmentally friendly goods, lack of information and political support [5]. In southern Chile, the efforts to improve the quality of firewood and its traceability began with the National Firewood Certification System (SNCL in Spanish) in 2003. Led by small producers and representatives from civil society in southern Chile, this system began with the motto that firewood is not the issue with air pollution, but rather its improper use. The program began as a voluntary public-private initiative to create a differentiated formal market that added value to the firewood and better profitability to forest management through a certification process. The certification seal ensures that the product sold is dry (and thus much less polluting when burned) and comes from sustainable forests. In addition, during the certification process the working conditions, where the firewood is produced are assessed to protect the rights of a traditionally precarious workforce, which is typical in upper-middle income countries [6]. At present, the SNCL has been re-founded as the new Seal of Firewood Quality, being taken on by the Energy Sustainability Agency of the Chilean Ministry of Energy. Thus, the certification process has been institutionalized and incorporated into public policy, fulfilling one of the historical aspirations of the firewood companies and local councils.

Despite the importance of solid biomass on a global scale, where almost 2.7 billion people use it for cooking and heating, there are relatively few studies on the functioning of firewood certification systems. In addition to the strategic relevance as a mitigation tool for air pollution in southern Chile, the certification programs are a key piece of environmental governance, whereby the production conditions of forest commodities can be determined by consumers' decisions [6]. With high levels of endemism, Chilean native forests receive heavy anthropogenic pressure, which places them among the 25 highpriority conservation eco-regions in the world [7].

Certified timber meets several sustainability criteria. In the first place, it guarantees the reduction of greenhouse gases, since it considers the emissions produced in transport and those generated in the preparation and packaging process. Second, they comply with the requirement of sustainable origin of the wood and that its extraction does not cause the impoverishment of the quality of the soil. Best practices are applied for the maintenance or improvement of the soil and its quality in relation to the production or management objectives, as these have been included in a management plan. In addition, forest management practices safeguard the quantity and quality of forest resources in the medium and long term by balancing harvesting and growth rates, and by preferring techniques that minimize direct or indirect damage to forest, soil or water resources. In firewood certification systems, appropriate silvicultural measures are taken to maintain or achieve a level of growing stock that is economically, ecologically and socially desirable. 
Indeed, timber certification is often mentioned as an interesting alternative to overcome unsustainable harvesting of forest resources [4]. Firewood certification schemes frequently consider environmental, social and economic impacts of timber harvesting. First, the certification seal imposes some codes of good practice that can directly impact on forest management sustainability. Second, certification may counterweight the pressures of agricultural expansion and indirectly reduce deforestation due to the higher prices of certified timber, which increases the marginal value given to forests.

Moreover, studies suggest that firewood certification systems increase wood combustion efficiency and ultimately air quality through establishing and enforcing wood quality standards (such as the humidity level) [2, 6, $8]$. The certification process gives consumers a signal of product quality and also helps protect the labor rights of workers. Overall, the potential boost in the consumption of certified firewood may be accompanied by an improvement in local air pollution and sustainable forest management, among other ecological and social benefits.

Although several studies have been conducted about how consumers tend towards environmentally friendly products [9-13], we know very little about the determinants of the purchase of certified firewood in markets in upper-middle income countries. We found studies about consumer's willingness to pay in Guatemala [14], Malaysia [15] and Chile [6, 16-19]. These studies focus primarily on the assessment of air quality that the population makes and how much they are willing to pay to improve it, accompanied by the analysis of political measures to promote this change. However, little study has been done on the influence of the combination of socio-demographic and psychosocial variables on the use of certified firewood. In the developing world, and specifically in Chile, barriers related to household income or product attributes have been identified, but not as many aspects related to risk perception and awareness. Thus, this study attempts to fill this research gap.

A small but growing body of literature points, in general terms, to three important driving factors: first, several studies show that potential consumers often do not invest in more environmentally sustainable products, because they either do not know or do not value the benefits of clean fuels or emerging energy technologies [20]; second, users may have difficulties dealing with the prices of improved fuels or, simply, cannot finance them without harming other basic needs in their home [21-24]; and third, there may be difficulties in the clean fuel distribution channels that discourage their adoption [25].

So, what factors influence the adoption of certified firewood in upper-middle income countries? Is it just a matter of product-related factors or are awareness and risk perception also important factors? The aim of this article is to characterize the determinants of the adoption of certified firewood in cities in southern Chile and identify variables associated with its use. With this, we seek to contribute to the understanding of the problem on the policy measures aimed at improving fuel quality in the search for solutions to control air pollution in upper-middle income countries.

\section{Method}

\section{Design and participants}

This study was conducted with a cross-sectional nonexperimental design, applying a survey in the communes of Temuco and Padre Las Casas. The survey was applied in person and individually in households in various sectors of this conurbation. Non-probability sampling by convenience was used, obtaining a total sample of 489 participants. For the purposes of this study, a sub-sample was used, considering participants who fulfilled the following inclusion criteria: (a) uses a wood-burning stove and (b) handles the heating system at home. Thus, the sample contained 355 participants aged between 18 and 89 years $(M=44.5, \mathrm{SD}=18.5)$. Other socio-demographic characteristics of the sample can be seen in Table 1. A comparison between our sample distribution and the National Socioeconomic Characterization Survey's (CASEN) can be found in Additional file 1: Table S1.

All the respondents signed an informed consent, participating voluntarily, anonymously, and confidentially.

Table 1 Socio-demographic characteristics of the sample

\begin{tabular}{lr}
\hline Variables & $\boldsymbol{n}(\%)$ \\
\hline Sex & \\
$\quad$ Male & $144(41)$ \\
$\quad$ Female & $211(59)$ \\
Education level & \\
$\quad$ Primary or lower & $49(14)$ \\
$\quad$ High school & $106(30)$ \\
$\quad$ University & $200(56)$ \\
Do people over 60 years old live with you? & \\
$\quad$ Yes & $134(38)$ \\
$\quad$ No & $221(62)$ \\
Indigenous & \\
$\quad$ Yes & $65(18)$ \\
$\quad$ No & $290(82)$ \\
Family income (USD) & \\
$\quad<640$ & $196(57)$ \\
$640-1300$ & $95(28)$ \\
$>1300$ & $52(15)$ \\
\hline
\end{tabular}




\section{Instrument}

A survey was applied regarding public perception and involvement in the control of air pollution using a Likert-type response from 1 to 5 , and multiple choice. This included various psycho-social questions, such as if they pay attention to air quality or look for information on the issue; if air pollution bothers them or if they are worried about its adverse effects on health; what their assessment is regarding air quality in their city or neighborhood.

A section for socio-demographic questions was also incorporated, including age, sex, household income, educational level, belonging to an indigenous people and the presence of chronic diseases in any members of the home. Answering the survey took around $20 \mathrm{~min}$.

\section{Data analysis}

The analyses in this study were performed with the statistical software SPSS v. 25. Initially, the database was debugged, where 12 cases with incomplete or inconsistent data were eliminated. Later, descriptive statistics were used for the description of the sample and characterization of the variables of interest to the study.

To analyze the use of certified firewood, comparisons were made according to socio-demographic variables by means of the Chi-square nonparametric test, reviewing the corrected standardized residues to reveal where the differences were $(>1.96)$. Then, to identify the relation between the use of certified firewood and various psycho-social variables, an Ordinal Logistic Regression was used, with logit link, which is used when the dependent variable values are fairly evenly distributed. For this analysis, we reviewed the assumption of multicollinearity to see if our independent variables were highly correlated, as well as the assumption of parallel lines, also known as the proportional odds assumption, which states that the slope coefficients in the model are the same across all response categories. The ordinal dependent variable was the use of certified firewood $(0=$ never to $3=$ always $)$. The independent variables included for this analysis were: (i) household income (total family income/residents in the home); (ii) do you live with people over 60 years old? $(0=$ yes, $1=$ not); (iii) do you pay attention to air quality? $(0=$ always to $4=$ never); (iv) do you feel bothered by air pollution? $(0=$ yes, $1=\mathrm{no})$; $(\mathrm{v})$ do you look for information about air quality? $(0=$ yes, $1=$ no); (vi) do you feel concerned about the effects of air pollution on your health? $(0=$ very to $4=$ not at all); and (vii) when can we observe the health effects of air pollution? $(0=$ long term, $1=$ medium term, $2=$ short term $)$.

\section{Results}

Descriptive analyses show that half of the participants use certified firewood in their homes "often" or "always" (50.4\%). When asking those who "never" (37.7\%) or "almost never" (11.9\%) use certified firewood for their reasons for not using this type of firewood, most of the participants mention that it is very expensive (66.3\%), followed by not knowing accessible suppliers (18.0\%), or because of the perception that wet firewood lasts longer (1.1\%). On the other hand, $14.6 \%$ of the participants mention not using certified firewood for other reasons, highlighting access to firewood from personal private sources.

A comparison of certified firewood use according to socio-demographic variables (see Table 2) showed no significant differences according to sex $\left(\chi^{2}=0.081\right.$; $p=0.776)$, belonging to an indigenous people $\left(\chi^{2}=0.829\right.$; $p=0.362$ ) or presence of chronic respiratory diseases $\left(\chi^{2}=2.244 ; p=0.134\right)$. However, there are significant differences according to family income level, where those with higher incomes use certified firewood more often $\left(\chi^{2}=10.503 ; p=0.005\right)$.

With respect to the Ordinal Regression to predict the use of certified firewood (see Table 3), it is observed that the model is significant $\left(\chi^{2}=744.690 ; p<0.001\right)$, showing an adequate goodness-of-fit according to Pearson's indicators $\left(\chi^{2}=854.524 ; p=0.164\right)$, deviance, $\left(\chi^{2}=713.825\right.$; $p=0.995)$ and Nagelkerke's pseudo- $R^{2}=0.167$. In addition, this model fulfills the assumption of parallel lines $\left(\chi^{2}=32.401 ; p=0.180\right)$ and reports that multicollinearity is not a concern (Tolerance $=0.641-0.930$; VIF $=1.075-1.561)$. Regarding the association between

Table 2 Comparison of the use of certified firewood according to socio-demographic variables

\begin{tabular}{lcc}
\hline & \multicolumn{2}{l}{ Use of certified firewood } \\
\cline { 2 - 3 } & No & Yes \\
& $\boldsymbol{n}(\%)$ & $\boldsymbol{n}(\%)$ \\
\hline Sex & & \\
$\quad$ Men & $76(36)$ & $135(64)$ \\
Women & $54(38)$ & $90(62)$ \\
Indigenous people & & \\
$\quad$ Yes & $27(42)$ & $38(58)$ \\
No & $103(36)$ & $187(64)$ \\
Respiratory diseases & & $33(73)$ \\
Yes & $12(27)$ & $191(62)$ \\
No & $118(38)$ & $111(57)$ \\
Family income (USD) & & $71(75)$ \\
$<640$ & $85(43)$ & $37(71)$ \\
$640-1300$ & $24(25)$ &
\end{tabular}


Table 3 Ordinal regression model for the use of certified firewood

\begin{tabular}{|c|c|c|c|c|}
\hline & Coefficient & Standard error & $p$ value & $95 \% \mathrm{Cl}$ \\
\hline \multicolumn{5}{|l|}{ Threshold } \\
\hline \multicolumn{5}{|l|}{ Certified wood use } \\
\hline$(x=0)$ Never & 0.709 & 0.450 & 0.115 & {$[-0.172 ; 1.590]$} \\
\hline$(x=1)$ Almost never & 1.117 & 0.450 & 0.013 & {$[0.236 ; 1.999]$} \\
\hline$(x=2)$ Often & 1.676 & 0.453 & $<0.001$ & {$[0.788 ; 2.564]$} \\
\hline \multicolumn{5}{|l|}{ Location } \\
\hline Household income & 0.104 & 0.482 & 0.031 & {$[0.096 ; 0.198]$} \\
\hline$(x=0)$ Yes & 0.429 & 0.152 & 0.005 & {$[0.131 ; 0.727]$} \\
\hline$(x=1) \mathrm{No}$ & Ref & & & \\
\hline \multicolumn{5}{|l|}{ Attention to air quality } \\
\hline$(x=0)$ Always & 0.729 & 0.284 & 0.010 & {$[0.173 ; 1.285]$} \\
\hline$(x=1)$ Often & 0.457 & 0.277 & 0.098 & {$[-0.085 ; 1.000]$} \\
\hline$(x=2)$ Almost ever & 0.382 & 0.312 & 0.221 & {$[-0.229 ; 0.993]$} \\
\hline$(x=3)$ Never & Ref & & & \\
\hline \multicolumn{5}{|c|}{ Look for air quality information } \\
\hline$(x=0)$ Yes & 0.488 & 0.157 & 0.002 & {$[0.179 ; 0.797]$} \\
\hline$(x=1)$ No & Ref & & & \\
\hline \multicolumn{5}{|l|}{ Bothered by air pollution } \\
\hline$(x=0)$ Yes & 0.516 & 0.235 & 0.028 & {$[0.055 ; 0.977]$} \\
\hline$(x=1)$ No & Ref & & & \\
\hline \multicolumn{5}{|c|}{ Concern about the health effects } \\
\hline$(x=0)$ Very & 0.729 & 0.369 & 0.049 & {$[0.005 ; 1.452]$} \\
\hline$(x=1)$ A lot & 0.414 & 0.366 & 0.259 & {$[-0.304 ; 1.132]$} \\
\hline$(x=2)$ Somewhat & 0.575 & 0.364 & 0.114 & {$[-0.138 ; 1.289]$} \\
\hline$(x=3)$ Almost none & 0.015 & 0.430 & 0.972 & {$[-0.828 ; 0.858]$} \\
\hline$(x=4)$ None & Ref & & & \\
\hline \multicolumn{5}{|c|}{ Health effects are observed in } \\
\hline$(x=0)$ Long term & 0.461 & 0.177 & 0.009 & {$[0.115 ; 0.807]$} \\
\hline$(x=1)$ Medium term & 0.540 & 0.168 & 0.006 & {$[0.158 ; 0.922]$} \\
\hline$(x=2)$ Short term & Ref & & & \\
\hline
\end{tabular}

the independent variables and the dependent variable, the regression model indicates that the respondents with a higher household income reported using certified firewood more frequently $(\beta=0.104 ; p=0.031)$. On the other hand, those who pay more attention $(\beta=0.729$; $p=0.010$ ) and look for information about air quality $(\beta=0.488 ; p=0.002)$ use more certified firewood. Finally, it is observed that those who are bothered by air pollution $(\beta=0.516 ; p=0.028)$, concerned about its effects on health $(\beta=0.729 ; p=0.049)$, and consider that these effects can occur in the long term $(\beta=0.461 ; p=0.009)$ use more frequently certified firewood.

Ordinal Logistic Regression's thresholds show us a division of the model line into three different segments. Each of them is associated with a coefficient that represents the needed amount to jump from one category to another. This is, from the category "never" to "almost never" $(\theta=0.709)$, "almost never" to "often" $(\theta=1.117)$ and "often" to "always" $(\theta=1.676)$. On the other hand, the coefficients of the independent variables at their different levels show us how much each of them contributes to approach the next leap between the categories of the dependent variable. Therefore, for instance, when participants report living with people over 60 years old, they add 0.429 to the equation. If we then add that they feel bothered by air pollution, which would give us an extra 0.516 points, adding a total of 0.945 to the use of certified firewood coefficient. With the total coefficient generated by these two variables, and hypothetically considering that all the other coefficients remain constant, we could say that the participant would jump from the category "never" to "almost never".

The categorical variables that most contribute to this equation are "always paying attention to air quality" and being "very concerned about air pollution's effects on 
health" ( $\beta=0.729$ in both cases). The household income, as a co-variable of the model, adds 0.104 every time its values go up. Therefore, the participant who has the minimum income value of this sample (37.72 USD), would add 0.104 to the final coefficient, but for someone who has 20 times more than that income (754.4 USD), we would add 2.080 to the equation, jumping straight to the "always" category. Thus, this model shows us that the household income is the variable that most explains the use of certified firewood coefficient variance.

\section{Discussion}

Our study is designed to characterize the use of certified firewood in cities in southern Chile and identify variables associated with its use. Almost half of the users of woodburning stoves participating in the study declared that they "never" (37.7\%) or "almost never" (11.9\%) use certified firewood to heat their home. Among the respondents, the main reason to justify the non-adoption of this fuel is the price, followed by the lack of known distribution channels. These results are in line with the findings of several studies on responsible consumption [26-32], where situational and product-related factors, such as price, availability, convenience and time are fundamental to people's purchase behavior.

In Temuco and Padre Las Casas, a cubic meter of certified firewood costs between 32 and 42 USD, whereas it can be found uncertified for 25-33 USD. In spite of information campaigns warning that wet firewood pollutes more, releases less caloric energy than dry firewood and has less efficient combustion, resulting in greater consumption, the price of the product continues to be a dissuasive factor in the users' purchase decision. In addition, respondents' state they do not know which stores sell certified firewood despite the efforts made by the National Consumer Service (SERNAC) to provide up-todate listings of the stores with a stock of dry firewood and pellets in Temuco and Padre Las Casas. However, it is worth noting that only $16 \%$ of the stores that appeared on the list in June 2020 sold certified firewood. Although all of them had home delivery service, the shortage of certified suppliers is consistent with the responses of the users in our survey.

Another important factor in not using certified firewood is access to firewood from one's own property or through friends and/or acquaintances that have private fields. In this sense, the purchase of firewood from small proprietors promotes the personal interaction and friendship between the country and the city, something that many users value beyond the quality and energy efficiency of the fuel they acquire [7]. Finally, a small group (1.1\%) still thinks that green firewood (uncertified) lasts longer than dry firewood. Nevertheless, in the last decade there has been a clear increasing trend in the consumption of certified firewood in homes; therefore, these results suggest that the myth that wet firewood lasts longer is being debunked. Indeed, these circumstances pose barriers to the mass adoption of certified firewood or other clean fuels in southern Chile.

When analyzing the factors that affect greater consumption of certified firewood, household income, the practice of becoming informed about air quality and the attention participants pay to this problem are consistently statistically significant predictor variables of the ordinal regression model. In addition, the multivariate analysis identified other factors that can aid in understanding the low involvement in the purchase of certified firewood that, according to some previous studies [33], tends to characterize southern Chile. In particular, the presence of adults over 60 years old and some psycho-social variables of perception, such as feeling annoyed about air pollution levels and being concerned about their effects on health, considering that their consequences could be long-term, is key to understanding why some users decide to buy certified firewood.

The socio-demographic variables have shown heterogeneous effects in previous studies conducted in developing countries; hence, it is difficult to draw conclusions about which factors favor the adoption of clean energies at home [34]. For example, the size of the house or the age of the family head has been analyzed by several studies with mixed results. However, various studies that consider economic status as an explanatory factor for the adoption of clean fuels indicate that the demand for these fuels is usually strongly linked to the income level [3538]. The results of the present study add to the weight of evidence that increasing a household's income can lead to a rise in the adoption of certified firewood products.

The findings also show that education could be key to encouraging the purchase of certified firewood. Those users who state feeling informed about air quality in the city tend to buy certified firewood more frequently. The provision of information about the importance of using dry firewood, the social, economic and ecological benefits of certification programs or a better dissemination of the points of sale could improve the adoption levels of the product. Based on our results and consistent with the findings reported by previous studies [6, 39], informing the user of pollution levels inside and outside the home to which they are exposed daily could be a good communication strategy to stimulate the purchase of certified firewood. However, although education campaigns usually help (especially in changing attitudes and certain beliefs), they are rarely enough to promote pro-environmental behaviors [39-42]. Education approaches usually work when the main barriers to the action are internal. 
In urban southern Chile, where instances of energy poverty are frequent, the information must be combined with other types of interventions aimed at confronting the resource constraints for material subsistence that the most vulnerable homes experience.

Be that as it may, we found that those most likely to buy certified firewood are those who are most aware of the risks to their own health that exposure to air pollution entails (or to that of their most vulnerable relatives). These results are in line with the findings of several studies that highlight the importance of risk perception and concern for improving air quality [43-45]. This leaves room to work on the communication strategies to increase information levels and awareness among the population. In this sense, it is important that people connect air pollution exposures to adverse health outcomes.

To do that, a study in Kenya found that public concern, mobilization of civil society and pressure from local experts are key, along with data to show the health implications of air pollution [46]. From these findings, we are persuaded that participation in conducting and interpreting air quality studies might help residents in Temuco and Padre Las Casas improve their understanding of air pollution and also help them develop responses to it. This strategy might as well help to support local action addressed by public health officials. On the other hand, based on the findings reported by previous studies, public awareness campaigns should be tailored explicitly to target vulnerable populations [45]. The results show that a timely combination of economic incentives and information campaigns sensitive to the living conditions of the most vulnerable segments of the population could help improve the levels of adoption of certified firewood.

This study has certain limitations that should be noted. First, our study shows suggestive results, but the small number of responses affects their confidence. Similarly, non-probabilistic surveys cannot be directly extrapolated to the population. Although the sample is not statistically representative of the entire population of the cities of Temuco and Padre las Casas, the surveyors collected data in all macro-sectors of the city. In this way, people who are usually underrepresented in survey studies were interviewed, with the objective of minimizing potential selection bias. If we compare our sample with national data (CASEN 2017), we can see similar distribution patterns in all our demographic variables, except for educational level, where we have more people with university studies, although this is expected, since we are working in urban areas. On the other hand, self-reports of certified-firewood adopting behavior rather than direct observations were the dependent variable in our ordinal regression model. Although this is typical in the literature on the subject, the findings here need to be taken cautiously. Furthermore, the cross-sectional nature of the study limits our ability to infer causal association. Finally, the conclusions could be in some way specific to the area of study (i.e., Temuco and Padre las Casas, Chile). New research is needed to test the consistency of our findings in other Chilean cities or other geographical settings sharing the same environmental problem. Despite these limitations and taking into account the scare literature on certified firewood adoption, the particular approach of our study may be valuable for both policy planners and academics.

\section{Concluding remarks}

We have presented the results of a localized study aimed at enhancing our understanding of the connections between household characteristics, psycho-social variables and the adoption of clean fuel. Our study aimed to identify crucial factors in the adoption of certified firewood in urban southern Chile, a region that includes some of the most polluted cities in Latin America. An ordinal regression analysis revealed the significant impacts of family income, the presence of elderly people in the household, air pollution information and awareness, in certified firewood adoption.

Our findings may help policymakers to ascertain a clearer understanding of some of the most important gaps between the interventions set by the government and individual behavioral responses. First, household income was the most important variable predicting the adoption of certified firewood. Therefore, awareness campaigns will tend to be less effective in deprived neighborhoods. For the most socially vulnerable segments, it seems essential to combine the provision of information on the hazards of air pollution with economic incentives to facilitate the purchase of certified firewood. Second, it is necessary to implement measures to ensure the distribution channels of certified firewood in the different neighborhoods of the cities. Certified firewood is not the only, nor perhaps the best strategy to control urban air pollution and promote the sustainable energy transition in southern Chile.

However, its promotion may be complementary to a more expensive long-term solution such as the improvement of energy efficiency in the construction of houses, or more popular than restrictions on the use of stoves.

\section{Supplementary Information}

The online version contains supplementary material available at https://doi. org/10.1186/s13705-021-00305-5.

Additional file 1: Table S1. Comparison between our sample distribution and CASEN's. 


\section{Acknowledgements \\ Not applicable.}

\section{Authors' contributions}

Apart from the original idea, which came from the corresponding author, all other sections of the paper including concepts, writing and proofreading were jointly done by the authors. All the authors contributed, and checked the final version of this manuscript. All authors read and approved the final manuscript.

\section{Funding}

This work was partially funded by the Agencia Nacional de Investigación y Desarrollo [Fondecyt 1190412] and the Program for Support High Productivity Groups of the Universidad de La Frontera.

\section{Availability of data and materials}

Data and additional materials are available on request.

\section{Declarations}

\section{Ethics approval and consent to participate}

The authors obtained written consent from all participants, in accordance with the Universidad de La Frontera's Research Ethics Committee.

\section{Consent for publication}

Not applicable.

\section{Competing interests}

The authors hereby declare that no competing interests exist.

Received: 22 March 2021 Accepted: 21 August 2021

Published online: 27 August 2021

\section{References}

1. IQAir. 2018 World Air Quality Report PM2.5 Ranking. 2018. https://www. iqair.com/.

2. Henne A (2010) Green lungs: good firewood, healthy air, and embodied forest politics. Environ Plan A 42:2078-2092

3. Cerutti PO, Tacconi L, Nasi R, Lescuyer G (2011) Legal vs certified timber: preliminary impacts of forest certification in Cameroon. For Policy Econ 13:184-190

4. Damette O, Delacote P (2011) Unsustainable timber harvesting, deforestation and the role of certification. Ecol Econ 70:1211-1219. https://doi. org/10.1016/j.ecolecon.2011.01.025

5. Fischer C, Aguilar F, Jawahar P, Sedjo R. Forest certification: toward common standards? Washington D.C.; 2005.

6. Vásquez Lavin F, Barrientos M, Castillo Á, Herrera I, Ponce Oliva RD (2020) Firewood certification programs: key attributes and policy implications. Energy Policy 137:111160

7. Reyes R, Nelson H, Zerriffi H (2018) Firewood: cause or consequence? Underlying drivers of firewood production in the South of Chile. Energy Sustain Dev 42:97-108

8. Conway FJ (2012) Certification and the state: market-driven governance and regulation in a Chilean firewood program. J Environ Dev 21:438-461

9. Verplanken B, Holland RW (2002) Motivated decision making: effects of activation and self-centrality of values on choices and behavior. J Pers Soc Psychol 82:434-447

10. Freestone OM, McGoldrick PJ (2008) Motivations of the ethical consumer. J Bus Ethics 79:445-467

11. Lau T-C (2010) Towards socially responsible consumption: an evaluation of religiosity and money ethics. Int J Trade Econ Financ 1:32-35

12. Kristensson $P$, Wästlund $E$, Söderlund M (2017) Influencing consumers to choose environment friendly offerings: evidence from field experiments. J Bus Res 76:89-97. https://doi.org/10.1016/j.jbusres.2017.03.003

13. Kumar A, Prakash G, Kumar G (2020) Does environmentally responsible purchase intention matter for consumers? A predictive sustainable model developed through an empirical study. J Retail Consum Serv 58:102270. https://doi.org/10.1016/j.jretconser.2020.102270
14. van Kempen L, Muradian R, Sandóval C, Castañeda JP (2009) Too poor to be green consumers? A field experiment on revealed preferences for firewood in rural Guatemala. Ecol Econ 68:2160-2167. https://doi.org/10. 1016/j.ecolecon.2009.02.014

15. Mohamed S, Ibrahim ML (2007) Preliminary study on willingness to pay for environmentally certified wood products among consumers in Malaysia. J Appl Sci 7:1339-1342

16. Cerda A, García L, Bahamondez A, Poblete V. Disposición a pagar para mejorar la calidad del aire en Talca, Chile: comparación entre usuarios y no usuarios de chimeneas a leña. Lect Econ. 2010;72:195-211. http:// www.scielo.org.co/pdf/le/n72/n72a08.pdf.

17. García LY, Valenzuela PA (2013) Valoración económica de una mejora en la calidad del aire en la ciudad de Rancagua. Rev Interam Ambient y Tur 9:108-119

18. Bustos $Y$, Ferrada LM. Consumo residencial de leña, análisis para la ciudad de Osorno en Chile. Idesia (Arica). 2017:35 ahead:0-0. https://doi.org/10. 4067/S0718-34292017005000024

19. García LY, Cerda AA, Lagos RdP, Muñoz PI, Muñoz M (2021) Society's willingness to pay for certified dry firewood energy in Chile. Front Energy Res 9:1-11

20. García-Maroto I, García-Maraver A, Muñoz-Leiva F, Zamorano M (2015) Consumer knowledge, information sources used and predisposition towards the adoption of wood pellets in domestic heating systems. Renew Sustain Energy Rev 43:207-215

21. Red de Pobreza Energética. Policy paper: Pobreza energética. El acceso desigual a energía de calidad como barrera para el desarrollo en Chile. Universidad de Chile; 2019. http://redesvid.uchile.cl/pobreza-energetica/.

22. Jaime MM, Chávez C, Gómez W (2020) Fuel choices and fuelwood use for residential heating and cooking in urban areas of central-southern Chile: the role of prices, income, and the availability of energy sources and technology. Resour Energy Econ 60:101125

23. Boso À, Oltra C, Hofflinger Á (2019) Participation in a programme for assisted replacement of wood-burning stoves in Chile: the role of sociodemographic factors, evaluation of air quality and risk perception. Energy Policy 129:1220-1226

24. Boso À, Hofflinger À, Garrido J, Álvarez B (2020) Breathing clean air or cheaply heating your home: an environmental justice Dilemma in Chilean Patagonia. Geogr Rev 00:1-21

25. Thomson H, Liddell C (2015) The suitability of wood pellet heating for domestic households: a review of literature. Renew Sustain Energy Rev 42:1362-1369. https://doi.org/10.1016/j.rser.2014.11.009

26. Hunt SD, Vitell SJ (1986) A general theory of marketing ethics. J Macromarketing 8:5-16

27. Hunt SD, Vitell SJ (2006) The general theory of marketing ethics: a revision and three questions. J Macromarketing 26:143-153

28. Roberts JA (1996) Will the real socially responsible consumer please step forward? Bus Horiz 39:79-83

29. Shaw D, Clarke I (1999) Belief formation in ethical consumer groups. Mark Intell Plan 17:109-120. https://doi.org/10.1108/02634509910260968

30. Browne A, Harris PJ, Hofny-Collins A, Pasiecznik N, Wallace R (2000) Organic production and ethical trade: definition, practice and links. Food Policy 25:69-89

31. Boulstridge E, Carrigan M (2000) Do consumers really care about corporate responsibility? Highlighting the attitude-behaviour gap. J Commun Manag 4:355-368

32. Carrigan M, Attalla A (2001) The myth of the ethical consumer-do ethics matter in purchase behaviour? J Consum Mark 18:560-578

33. Boso À, Ariztía T, Fonseca F (2017) Uses, resistances and acceptance of emergent household energy technologies: the case of the wood-burning stove exchange program in Temuco. Chile Rev Int Sociol 75:e078-e078

34. Lewis JJ, Pattanayak SK (2012) Who adopts improved fuels and cookstoves? A systematic review. Environ Health Perspect 120:637-645

35. Ouedraogo B (2006) Household energy preferences for cooking in urban Ouagadougou, Burkina Faso. Energy Policy 34:3787-3795

36. Narasimha Rao M, Reddy BS (2007) Variations in energy use by Indian households: an analysis of micro level data. Energy 32:143-153

37. Khandker SR, Barnes DF, Samad HA. Energy poverty in rural and urban India: Are the energy poor also income poor? 2010. http://www-wds. worldbank.org/servlet/WDSContentServer/WDSP/IB/2010/11/01/00015 8349 20101101152446/Rendered/PDF/WPS5463.pdf. 
38. Peng W, Hisham Z, Pan J (2010) Household level fuel switching in rural Hubei. Energy Sustain Dev 14:238-244

39. Boso À, Álvarez B, Oltra C, Garrido J, Muñoz C, Hofflinger Á (2020) Out of sight, out of mind: participatory sensing for monitoring indoor air quality. Environ Monit Assess 192:104

40. Gardner G, Stern P (2002) Environmental problems and human behavior, 2nd edn. Pearson Custom Publishing, Boston

41. McKenzie-Mohr D, Schultz PW (2014) Choosing effective behavior change tools. Soc Mar Q 20:35-46

42. Steg L, Vlek C (2009) Encouraging pro-environmental behaviour: an integrative review and research agenda. J Environ Psychol 29:309-317. https://doi.org/10.1016/j.jenvp.2008.10.004

43. Mao B, Ao C, Cheng Y, Jiang N, Xu L (2020) Exploring the role of public risk perceptions on preferences for air quality improvement policies: an integrated choice and latent variable approach. J Clean Prod 269:122379. https://doi.org/10.1016/j.jclepro.2020.122379

44. Pu S, Shao Z, Fang M, Yang L, Liu R, Bi J et al (2019) Spatial distribution of the public's risk perception for air pollution: a nationwide study in China.
Sci Total Environ 655:454-462. https://doi.org/10.1016/j.scitotenv.2018.11. 232

45. Reames TG, Bravo MA (2019) People, place and pollution: investigating relationships between air quality perceptions, health concerns, exposure, and individual- and area-level characteristics. Environ Int 122:244-255. https://doi.org/10.1016/j.envint.2018.11.013

46. Ngo NS, Kokoyo S, Klopp J (2017) Why participation matters for air quality studies: risk perceptions, understandings of air pollution and mobilization in a poor neighborhood in Nairobi, Kenya. Public Health 142:177-185. https://doi.org/10.1016/j.puhe.2015.07.014

\section{Publisher's Note}

Springer Nature remains neutral with regard to jurisdictional claims in published maps and institutional affiliations.
Ready to submit your research? Choose BMC and benefit from:

- fast, convenient online submission

- thorough peer review by experienced researchers in your field

- rapid publication on acceptance

- support for research data, including large and complex data types

- gold Open Access which fosters wider collaboration and increased citations

- maximum visibility for your research: over $100 \mathrm{M}$ website views per year

At BMC, research is always in progress.

Learn more biomedcentral.com/submissions 